\title{
Common solutions of equilibrium and fixed point problems
}

Qing-Nian Zhang*

\section{"Correspondence:}

wszhangqn@yeah.net

School of Mathematics and

Information Science, North China

University of Water Resources and

Electric Power, Zhengzhou, China

\begin{abstract}
In this paper, common solutions of equilibrium and fixed point problems are investigated. Convergence theorems of common solutions are established in a uniformly smooth and strictly convex Banach space.

MSC: $47 \mathrm{H} 09 ; 47 \mathrm{H} 10 ; 47 \mathrm{~J} 25$

Keywords: asymptotically quasi- $\phi$-nonexpansive mapping; generalized asymptotically quasi- $\phi$-nonexpansive mapping; generalized projection; equilibrium problem; fixed point
\end{abstract}

\section{Introduction and preliminaries}

Let $E$ be a real Banach space. Let $U_{E}=\{x \in E:\|x\|=1\}$ be the unit sphere of $E$. $E$ is said to be smooth iff $\lim _{t \rightarrow 0} \frac{\|x+t y\|-\|x\|}{t}$ exists for each $x, y \in U_{E}$. It is also said to be uniformly smooth iff the above limit is attained uniformly for $x, y \in U_{E}$. $E$ is said to be strictly convex iff $\left\|\frac{x+y}{2}\right\|<1$ for all $x, y \in E$ with $\|x\|=\|y\|=1$ and $x \neq y$. It is said to be uniformly convex iff $\lim _{n \rightarrow \infty}\left\|x_{n}-y_{n}\right\|=0$ for any two sequences $\left\{x_{n}\right\}$ and $\left\{y_{n}\right\}$ in $E$ such that $\left\|x_{n}\right\|=\left\|y_{n}\right\|=1$ and $\lim _{n \rightarrow \infty}\left\|\frac{x_{n}+y_{n}}{2}\right\|=1$.

Recall that the normalized duality mapping $J$ from $E$ to $2^{E^{*}}$ is defined by

$$
J x=\left\{f^{*} \in E^{*}:\left\langle x, f^{*}\right\rangle=\|x\|^{2}=\left\|f^{*}\right\|^{2}\right\}
$$

where $\langle\cdot, \cdot\rangle$ denotes the generalized duality pairing. It is well known that if $E$ is uniformly smooth, then $J$ is uniformly norm-to-norm continuous on each bounded subset of $E$. It is also well known that $E$ is (uniformly) smooth if and only if $E^{*}$ is (uniformly) convex.

In what follows, we use $\rightarrow$ and $\rightarrow$ to stand for the weak and strong convergence, respectively. Recall that $E$ enjoys the Kadec-Klee property iff for any sequence $\left\{x_{n}\right\} \subset E$, and $x \in E$ with $x_{n} \rightarrow x$, and $\left\|x_{n}\right\| \rightarrow\|x\|$, then $\left\|x_{n}-x\right\| \rightarrow 0$ as $n \rightarrow \infty$. It is well known that if $E$ is a uniformly convex Banach space, then $E$ enjoys the Kadec-Klee property.

Let $E$ be a smooth Banach space. Consider the functional defined by

$$
\phi(x, y)=\|x\|^{2}-2\langle x, J y\rangle+\|y\|^{2} \quad \forall x, y \in E .
$$

Observe that, in a Hilbert space $H$, the equality is reduced to $\phi(x, y)=\|x-y\|^{2}, x, y \in H$. As we all know, if $C$ is a nonempty closed convex subset of a Hilbert space $H$ and $P_{C}: H \rightarrow C$ is the metric projection of $H$ onto $C$, then $P_{C}$ is nonexpansive. This fact actually characterizes Hilbert spaces and, consequently, it is not available in more general Banach spaces.

(c) 2013 Zhang; licensee Springer. This is an Open Access article distributed under the terms of the Creative Commons Attribution License (http://creativecommons.org/licenses/by/2.0), which permits unrestricted use, distribution, and reproduction in any medium, provided the original work is properly cited. 
In this connection, Alber [1] recently introduced a generalized projection operator $\Pi_{C}$ in a Banach space $E$, which is an analogue of the metric projection $P_{C}$ in Hilbert spaces. Recall that the generalized projection $\Pi_{C}: E \rightarrow C$ is a map that assigns to an arbitrary point $x \in E$ the minimum point of the functional $\phi(x, y)$, that is, $\Pi_{C} x=\bar{x}$, where $\bar{x}$ is the solution to the minimization problem $\phi(\bar{x}, x)=\min _{y \in C} \phi(y, x)$. Existence and uniqueness of the operator $\Pi_{C}$ follows from the properties of the functional $\phi(x, y)$ and strict monotonicity of the mapping $J$. If $E$ is a reflexive, strictly convex and smooth Banach space, then $\phi(x, y)=0$ if and only if $x=y$; for more details, see [1] and the references therein. In Hilbert spaces, $\Pi_{C}=P_{C}$. It is obvious from the definition of a function $\phi$ that

$$
\phi(x, y)=\phi(x, z)+\phi(z, y)+2\langle x-z, J z-J y\rangle, \quad \forall x, y, z \in E,
$$

and

$$
(\|x\|-\|y\|)^{2} \leq \phi(x, y) \leq(\|y\|+\|x\|)^{2}, \quad \forall x, y \in E .
$$

Let $C$ be a nonempty subset of $E$, and let $T: C \rightarrow C$ be a mapping. In this paper, we use $F(T)$ to stand for the fixed point set of $T . T$ is said to be closed iff for any sequence $\left\{x_{n}\right\} \subset C$ such that $\lim _{n \rightarrow \infty} x_{n}=x_{0}$ and $\lim _{n \rightarrow \infty} T x_{n}=y_{0}$, then $T x_{0}=y_{0} . T$ is said to be asymptotically regular on $C$ iff for any bounded subset $K$ of $C$,

$$
\limsup _{n \rightarrow \infty}\left\{\left\|T^{n+1} x-T^{n} x\right\|: x \in K\right\}=0 .
$$

Recall that a point $p$ in $C$ is said to be an asymptotic fixed point of $T$ iff $C$ contains a sequence $\left\{x_{n}\right\}$ which converges weakly to $p$ such that $\lim _{n \rightarrow \infty}\left\|x_{n}-T x_{n}\right\|=0$. The set of asymptotic fixed points of $T$ will be denoted by $\widetilde{F}(T)$. $T$ is said to be relatively nonexpansive iff

$$
\widetilde{F}(T)=F(T) \neq \emptyset, \quad \phi(p, T x) \leq \phi(p, x), \quad \forall x \in C, \forall p \in F(T) .
$$

$T$ is said to be relatively asymptotically nonexpansive iff

$$
\widetilde{F}(T)=F(T) \neq \emptyset, \quad \phi\left(p, T^{n} x\right) \leq\left(1+\mu_{n}\right) \phi(p, x), \quad \forall x \in C, \forall p \in F(T), \forall n \geq 1,
$$

where $\left\{\mu_{n}\right\} \subset[0, \infty)$ is a sequence such that $\mu_{n} \rightarrow 0$ as $n \rightarrow \infty$.

Remark 1.1 The class of relatively asymptotically nonexpansive mappings which is an extension of the class of relatively nonexpansive mappings was first considered in [2] and [3].

Recall that $T$ is said to be quasi- $\phi$-nonexpansive iff

$$
F(T) \neq \emptyset, \quad \phi(p, T x) \leq \phi(p, x), \quad \forall x \in C, \forall p \in F(T) .
$$

Recall that $T$ is said to be asymptotically quasi- $\phi$-nonexpansive iff there exists a sequence $\left\{\mu_{n}\right\} \subset[0, \infty)$ with $\mu_{n} \rightarrow 0$ as $n \rightarrow \infty$ such that

$$
F(T) \neq \emptyset, \quad \phi\left(p, T^{n} x\right) \leq\left(1+\mu_{n}\right) \phi(p, x), \quad \forall x \in C, \forall p \in F(T), \forall n \geq 1 .
$$


Remark 1.2 The class of asymptotically quasi- $\phi$-nonexpansive mappings, which is an extension of the class of quasi- $\phi$-nonexpansive mappings, was considered in $[4,5]$; see also [6].

Remark 1.3 The class of quasi- $\phi$-nonexpansive mappings and the class of asymptotically quasi- $\phi$-nonexpansive mappings are more general than the class of relatively nonexpansive mappings and the class of relatively asymptotically nonexpansive mappings. Quasi$\phi$-nonexpansive mappings and asymptotically quasi- $\phi$-nonexpansive mappings do not require the restriction $F(T)=\widetilde{F}(T)$.

Remark 1.4 The class of quasi- $\phi$-nonexpansive mappings and the class of asymptotically quasi- $\phi$-nonexpansive mappings are generalizations of the class of quasi-nonexpansive mappings and the class of asymptotically quasi-nonexpansive mappings in Banach spaces.

Recall that $T$ is said to be generalized asymptotically quasi- $\phi$-nonexpansive iff $F(T) \neq \emptyset$, and there exist two nonnegative sequences $\left\{\mu_{n}\right\} \subset[0, \infty)$ with $\mu_{n} \rightarrow 0$, and $\left\{\xi_{n}\right\} \subset[0, \infty)$ with $\xi_{n} \rightarrow 0$ as $n \rightarrow \infty$ such that

$$
\phi\left(p, T^{n} x\right) \leq\left(1+\mu_{n}\right) \phi(p, x)+\xi_{n}, \quad \forall x \in C, \forall p \in F(T), \forall n \geq 1 .
$$

Remark 1.5 The class of generalized asymptotically quasi- $\phi$-nonexpansive mappings [7] is a generalization of the class of generalized asymptotically quasi-nonexpansive mappings in the framework of Banach spaces which was introduced by Agarwal et al. [8].

Let $F$ be a bifunction from $C \times C$ to $\mathbb{R}$, where $\mathbb{R}$ denotes the set of real numbers. Recall the following equilibrium problem. Find $p \in C$ such that $F(p, y) \geq 0, \forall y \in C$. We use $E P(F)$ to denote the solution set of the equilibrium problem. Given a mapping $Q: C \rightarrow E^{*}$, let

$$
F(x, y)=\langle Q x, y-x\rangle, \quad \forall x, y \in C .
$$

Then $p \in E P(F)$ if and only if $p$ is a solution of the following variational inequality. Find $p$ such that

$$
\langle Q p, y-p\rangle \geq 0, \quad \forall y \in C
$$

Numerous problems in physics, optimization and economics reduce to finding a solution of the equilibrium problem; see [9-36] and the related references therein. In [25], Kim studied a sequence $\left\{x_{n}\right\}$ which is generated in the following manner:

$$
\left\{\begin{array}{l}
x_{0} \in E, \quad \text { chosen arbitrarily, } \\
C_{1}=C, \\
x_{1}=\Pi_{C_{1} x_{0}}, \\
y_{n}=J^{-1}\left(\alpha_{n} J x_{n}+\left(1-\alpha_{n}\right) J T^{n} x_{n}\right), \\
u_{n} \in C \text { such that } F\left(u_{n}, y\right)+\frac{1}{r_{n}}\left(y-u_{n}, J u_{n}-J y_{n}\right\rangle \geq 0, \quad \forall y \in C, \\
C_{n+1}=\left\{z \in C_{n}: \phi\left(z, u_{n}\right) \leq \phi\left(z, x_{n}\right)+\left(k_{n}-1\right) M_{n}\right\}, \\
x_{n+1}=\Pi_{C_{n+1}} x_{0},
\end{array}\right.
$$


where $M_{n}=\sup \left\{\phi\left(z, x_{n}\right): z \in \mathcal{F}\right\}$ for each $n \geq 1,\left\{\alpha_{n}\right\}$ is a real sequence in $[0,1],\left\{r_{n}\right\}$ is a real sequence in $[a, \infty)$, where $a$ is some positive real number. In a uniformly smooth and strictly convex Banach space, which also enjoys the Kadec-Klee property, the author obtained a strong convergence theorem; for more details, see [25] and the references therein.

In this paper, motivated by the above result, we consider the projection algorithm for treating solutions of the equilibrium problem and fixed points of generalized asymptotically quasi- $\phi$-nonexpansive mappings. A strong convergence theorem is established in a Banach space. The results presented this paper mainly improve the corresponding results announced in Qin Cho and Kang [5] and Kim [25].

In order to prove our main results, we need the following lemmas.

Lemma 1.6 [36] Let E be a smooth and uniformly convex Banach space, and let $r>0$. Then there exists a strictly increasing, continuous and convex function $g:[0,2 r] \rightarrow R$ such that $g(0)=0$ and

$$
\|t x+(1-t) y\|^{2} \leq t\|x\|^{2}+(1-t)\|y\|^{2}-t(1-t) g(\|x-y\|)
$$

for all $x, y \in B_{r}=\{x \in E:\|x\| \leq r\}$ and $t \in[0,1]$.

Lemma 1.7 [1] Let C be a nonempty closed convex subset of a smooth Banach space E and $x \in E$. Then $x_{0}=\Pi_{C} x$ if and only if

$$
\left\langle x_{0}-y, J x-J x_{0}\right\rangle \geq 0 \quad \forall y \in C .
$$

Lemma 1.8 [1] Let E be a reflexive, strictly convex and smooth Banach space, let $C$ be a nonempty closed convex subset of $E$ and $x \in E$. Then

$$
\phi\left(y, \Pi_{C} x\right)+\phi\left(\Pi_{C} x, x\right) \leq \phi(y, x) \quad \forall y \in C
$$

Lemma 1.9 [5,22] Let $C$ be a closed convex subset of a smooth, strictly convex and reflexive Banach space E. Let $F$ be a bifunction from $C \times C$ to $\mathbb{R}$ satisfying (A1)-(A4). Let $r>0$ and $x \in E$. Then there exists $z \in C$ such that $F(z, y)+\frac{1}{r}\langle y-z, J z-J x\rangle \geq 0, \forall y \in C$. Define a mapping $T_{r}: E \rightarrow C$ by

$$
S_{r} x=\left\{z \in C: f(z, y)+\frac{1}{r}\langle y-z, J z-J x\rangle, \forall y \in C\right\} .
$$

Then the following conclusions hold:

(1) $S_{r}$ is a single-valued firmly nonexpansive-type mapping, i.e., for all $x, y \in E$,

$$
\left\langle S_{r} x-S_{r} y, J S_{r} x-J S_{r} y\right\rangle \leq\left\langle S_{r} x-S_{r} y, J x-J y\right\rangle
$$

(2) $F\left(S_{r}\right)=E P(F)$ is closed and convex;

(3) $S_{r}$ is quasi- $\phi$-nonexpansive;

(4) $\phi\left(q, S_{r} x\right)+\phi\left(S_{r} x, x\right) \leq \phi(q, x), \forall q \in F\left(S_{r}\right)$. 
Lemma 1.10 [7] Let E be a uniformly smooth and strictly convex Banach space which also enjoys the Kadec-Klee property, and let $C$ be a nonempty closed and convex subset of E. Let $T: C \rightarrow C$ be a generalized asymptotically quasi- $\phi$-nonexpansive mapping. Then $F(T)$ is closed and convex.

\section{Main results}

Theorem 2.1 Let E be a uniformly smooth and strictly convex Banach space which also enjoys the Kadec-Klee property, and let $C$ be a nonempty closed and convex subset of E. Let $\Delta$ be an index set. Let $F_{i}$ be a bifunction from $C \times C$ to $\mathbb{R}$ satisfying (A1)-(A4) for every $i \in \Delta$. Let $T: C \rightarrow C$ be a generalized asymptotically quasi- $\phi$-nonexpansive mapping. Assume that $T$ is closed asymptotically regular on $C$ and $\Omega:=F(T) \cap \bigcap_{i \in \Delta} E F\left(F_{i}\right)$ is nonempty and bounded. Let $\left\{x_{n}\right\}$ be a sequence generated in the following manner:

$$
\left\{\begin{array}{l}
x_{0} \in E, \quad \text { chosen arbitrarily, } \\
C_{1, i}=C, \\
C_{1}=\bigcap_{i \in \Delta} C_{1, i}, \\
x_{1}=\prod_{C_{1}} x_{0}, \\
y_{n}=J^{-1}\left(\alpha_{n} J x_{n}+\left(1-\alpha_{n}\right) J T^{n} x_{n}\right), \\
u_{n, i} \in C \text { such that } F_{i}\left(u_{n, i}, y\right)+\frac{1}{r_{n, i}}\left\langle y-u_{n, i} J u_{n, i}-J y_{n}\right\rangle \geq 0, \quad \forall y \in C, \\
C_{n+1, i}=\left\{z \in C_{n}: \phi\left(z, u_{n, i}\right) \leq \phi\left(z, x_{n}\right)+\mu_{n} M_{n}+\xi_{n}\right\}, \\
C_{n+1}=\bigcap_{i \in \Delta} C_{n+1, i}, \\
x_{n+1}=\Pi_{C_{n+1}} x_{0},
\end{array}\right.
$$

where $M_{n}=\sup \left\{\phi\left(z, x_{n}\right): z \in \Omega\right\},\left\{\alpha_{n}\right\}$ is a real number sequence in $(0,1)$ such that $\liminf _{n \rightarrow \infty} \alpha_{n}\left(1-\alpha_{n}\right)>0,\left\{r_{n, i}\right\}$ is a real number sequence in $\left[a_{i}, \infty\right)$, where $\left\{a_{i}\right\}$ is a positive real number sequence. Then the sequence $\left\{x_{n}\right\}$ converges strongly to $\Pi_{\Omega} x_{0}$, where $\Pi_{\Omega}$ is the generalized projection from $E$ onto $\Omega$.

Proof In view of Lemmas 1.9 and 1.10, we find that the common solution set $\Omega$ is closed and convex. Next, we show that $C_{n}$ is closed and convex. It suffices to show, for any fixed but arbitrary $i \in \Delta$, that $C_{n, i}$ is closed and convex. This can be proved by induction on $n$. It is obvious that $C_{1, i}=C$ is closed and convex. Assume that $C_{j, i}$ is closed and convex for some $j \geq 1$. We next prove that $C_{j+1, i}$ is closed and convex for the same $j$. This completes the proof that $C_{n}$ is closed and convex. It is clear that $C_{j+1, i}$ is closed. We only prove the convexity. Indeed, $\forall a, b \in C_{j+1, i}$, we see that $a, b \in C_{j, i}$, and

$$
\phi\left(a, u_{j, i}\right) \leq \phi\left(a, x_{j}\right)+\mu_{j} M_{j}+\xi_{j},
$$

and

$$
\phi\left(b, u_{j, i}\right) \leq \phi\left(b, x_{j}\right)+\mu_{j} M_{j}+\xi_{j} .
$$

Notice that the two inequalities above are equivalent to the following inequalities, respectively:

$$
2\left\langle a, J x_{j}-J u_{j, i}\right\rangle \leq\left\|x_{j}\right\|^{2}-\left\|u_{j, i}\right\|^{2}+\mu_{j} M_{j}+\xi_{j},
$$


and

$$
2\left\langle b, J x_{j}-J u_{j, i}\right\rangle \leq\left\|x_{j}\right\|^{2}-\left\|u_{j, i}\right\|^{2}+\mu_{j} M_{j}+\xi_{j}
$$

These imply that

$$
2\left\langle t a+(1-t) b, J x_{j}-J u_{j, i}\right\rangle \leq\left\|x_{j}\right\|^{2}-\left\|u_{j, i}\right\|^{2}+\mu_{j} M_{j}+\xi_{j}, \quad \forall t \in(0,1) .
$$

Since $C_{j, i}$ is convex, we see that $t a+(1-t) b \in C_{j, i}$. Notice that the above inequality is equivalent to

$$
\phi\left(t a+(1-t) b, u_{j, i}\right) \leq \phi\left(t a+(1-t) b, x_{j}\right)+\mu_{j} M_{j}+\xi_{j}
$$

This proves that $C_{j+1, i}$ is convex. This completes that $C_{n}$ is closed and convex.

Next, we prove that $\Omega \subset C_{n}$. It suffices to claim that $\Omega \subset C_{n, i}$ for every $i \in \Delta$. Note that $\Omega \subset C_{1, i}=C$. Suppose that $\Omega \subset C_{j, i}$ for some $j$ and for every $i \in \Delta$. Then, for $\forall w \in \Omega \subset C_{j, i}$, we have

$$
\begin{aligned}
& \phi\left(w, u_{j, i}\right) \\
&=\phi\left(w, S_{r_{j, i}} y_{j}\right) \\
&=\phi\left(w, J^{-1}\left(\alpha_{j} J x_{j}+\left(1-\alpha_{j}\right) J T^{j} x_{j}\right)\right) \\
&=\|w\|^{2}-2\left\langle w, \alpha_{j} J x_{j}+\left(1-\alpha_{j}\right) J T^{j} x_{j}\right\rangle \\
& \quad+\left\|\alpha_{j} J x_{j}+\left(1-\alpha_{j}\right) J T^{j} x_{j}\right\|^{2} \\
& \leq\|w\|^{2}-2 \alpha_{j}\left\langle w, J x_{j}\right\rangle-2\left(1-\alpha_{j}\right)\left\langle w, J T^{j} x_{j}\right\rangle+\alpha_{j}\left\|x_{j}\right\|^{2} \\
&+\left(1-\alpha_{j}\right)\left\|T^{j} x_{j}\right\|^{2} \\
&= \alpha_{j} \phi\left(w, x_{j}\right)+\left(1-\alpha_{j}\right) \phi\left(w, T^{j} x_{j}\right) \\
& \leq \alpha_{j} \phi\left(w, x_{j}\right)+\left(1-\alpha_{j}\right)\left(1+\mu_{j}\right) \phi\left(w, x_{j}\right)+\xi_{j}\left(1-\alpha_{j}\right) \\
& \leq \phi\left(w, x_{j}\right)+\mu_{j} \phi\left(w, x_{j}\right)+\xi_{j} \\
& \leq \phi\left(w, x_{j}\right)+\mu_{j} M_{j}+\xi_{j} .
\end{aligned}
$$

This shows that $w \in C_{j+1, i}$. This implies that $\Omega \subset C_{n}$ for every $n \geq 1$.

On the other hand, it follows from Lemma 1.8 that

$$
\phi\left(x_{n}, x_{0}\right)=\phi\left(\Pi_{C_{n}} x_{0}, x_{0}\right) \leq \phi\left(w, x_{0}\right)-\phi\left(w, x_{n}\right) \leq \phi\left(w, x_{0}\right), \quad \forall w \in \Omega \subset C_{n} .
$$

This shows that the sequence $\phi\left(x_{n}, x_{0}\right)$ is bounded. In view of (1.2), we see that the sequence $\left\{x_{n}\right\}$ is also bounded. Since the space is reflexive, we may, without loss of generality, assume that $x_{n} \rightarrow p \in C_{n}$. Note that $\phi\left(x_{n}, x_{0}\right) \leq \phi\left(p, x_{0}\right)$. It follows that

$$
\phi\left(p, x_{0}\right) \leq \liminf _{n \rightarrow \infty} \phi\left(x_{n}, x_{0}\right) \leq \limsup _{n \rightarrow \infty} \phi\left(x_{n}, x_{0}\right) \leq \phi\left(p, x_{0}\right) .
$$


This implies that

$$
\lim _{n \rightarrow \infty} \phi\left(x_{n}, x_{0}\right)=\phi\left(p, x_{0}\right)
$$

Hence, we have $\left\|x_{n}\right\| \rightarrow\|p\|$ as $n \rightarrow \infty$. In view of the Kadec-Klee property of $E$, we obtain that $x_{n} \rightarrow p$ as $n \rightarrow \infty$.

Next, we show that $p \in F(T)$. By the construction of $C_{n}$, we have that $C_{n+1} \subset C_{n}$ and $x_{n+1}=\Pi_{C_{n+1}} x_{0} \in C_{n}$. It follows that

$$
\begin{aligned}
\phi\left(x_{n+1}, x_{n}\right) & =\phi\left(x_{n+1}, \Pi_{C_{n}} x_{0}\right) \\
& \leq \phi\left(x_{n+1}, x_{0}\right)-\phi\left(\Pi_{C_{n}} x_{0}, x_{0}\right) \\
& =\phi\left(x_{n+1}, x_{0}\right)-\phi\left(x_{n}, x_{0}\right) .
\end{aligned}
$$

Letting $n \rightarrow \infty$, we obtain that $\phi\left(x_{n+1}, x_{n}\right) \rightarrow 0$. In view of $x_{n+1} \in C_{n+1}$, we see that

$$
\phi\left(x_{n+1}, u_{n, i}\right) \leq \phi\left(x_{n+1}, x_{n}\right)+\mu_{n} M_{n}+\xi_{n} .
$$

It follows that

$$
\lim _{n \rightarrow \infty} \phi\left(x_{n+1}, u_{n, i}\right)=0
$$

From (1.2), we see that $\lim _{n \rightarrow \infty}\left\|u_{n, i}\right\|=\|p\|$. It follows that $\lim _{n \rightarrow \infty}\left\|J u_{n, i}\right\|=\|J p\|$. This implies that $\left\{J u_{n, i}\right\}$ is bounded. Note that $E$ is reflexive and $E^{*}$ is also reflexive. We may assume that $J u_{n, i} \rightarrow x^{*, i} \in E^{*}$. In view of the reflexivity of $E$, we see that $J(E)=E^{*}$. This shows that there exists an $x^{i} \in E$ such that $J x^{i}=x^{*, i}$. It follows that

$$
\begin{aligned}
\phi\left(x_{n+1}, u_{n, i}\right) & =\left\|x_{n+1}\right\|^{2}-2\left\langle x_{n+1}, J u_{n}\right\rangle+\left\|u_{n}\right\|^{2} \\
& =\left\|x_{n+1}\right\|^{2}-2\left\langle x_{n+1}, J u_{n}\right\rangle+\left\|J u_{n}\right\|^{2} .
\end{aligned}
$$

Taking $\liminf \operatorname{si\infty }_{n \rightarrow \infty}$ on the both sides of the equality above yields that

$$
\begin{aligned}
0 & \geq\|p\|^{2}-2\left\langle p, x^{*, i}\right\rangle+\left\|x^{*, i}\right\|^{2} \\
& =\|p\|^{2}-2\left\langle p, J x^{i}\right\rangle+\left\|J x^{i}\right\|^{2} \\
& =\|p\|^{2}-2\left\langle p, J x^{i}\right\rangle+\left\|x^{i}\right\|^{2} \\
& =\phi\left(p, x^{i}\right) .
\end{aligned}
$$

That is, $p=x^{i}$, which in turn implies that $x^{*, i}=J p$. It follows that $J u_{n, i} \rightarrow J p \in E^{*}$. Since $E^{*}$ enjoys the Kadec-Klee property, we obtain that $J u_{n, i}-J p \rightarrow 0$ as $n \rightarrow \infty$. Note that $J^{-1}: E^{*} \rightarrow E$ is demi-continuous. It follows that $u_{n, i} \rightarrow p$. Since $E$ enjoys the Kadec-Klee property, we obtain that $u_{n, i} \rightarrow p$ as $n \rightarrow \infty$. Note that

$$
\left\|x_{n}-u_{n, i}\right\| \leq\left\|x_{n}-p\right\|+\left\|p-u_{n, i}\right\| .
$$


It follows that

$$
\lim _{n \rightarrow \infty}\left\|x_{n}-u_{n, i}\right\|=0
$$

Since $J$ is uniformly norm-to-norm continuous on any bounded sets, we have

$$
\lim _{n \rightarrow \infty}\left\|J x_{n}-J u_{n, i}\right\|=0 .
$$

Let $r=\sup _{n \geq 0}\left\{\left\|x_{n}\right\|,\left\|T^{n} x_{n}\right\|\right\}$. Since $E$ is uniformly smooth, we know that $E^{*}$ is uniformly convex. In view of Lemma 1.6, we see that

$$
\begin{aligned}
& \phi\left(w, u_{n, i}\right) \\
&=\phi\left(w, S_{r_{n},} y_{n}\right) \\
&=\phi\left(w, J^{-1}\left(\alpha_{n} J x_{n}+\left(1-\alpha_{j}\right) J T^{n} x_{n}\right)\right) \\
&=\|w\|^{2}-2\left\langle w, \alpha_{n} J x_{n}+\left(1-\alpha_{n}\right) J T^{n} x_{n}\right\rangle \\
& \quad+\left\|\alpha_{n} J x_{n}+\left(1-\alpha_{n}\right) J T^{n} x_{n}\right\|^{2} \\
& \leq\|w\|^{2}-2 \alpha_{n}\left\langle w, J x_{n}\right\rangle-2\left(1-\alpha_{n}\right)\left\langle w, J T^{n} x_{n}\right\rangle+\alpha_{n}\left\|x_{n}\right\|^{2} \\
&+\left(1-\alpha_{n}\right)\left\|T^{n} x_{n}\right\|^{2}-\alpha_{n}\left(1-\alpha_{n}\right) g\left(\left\|J x_{n}-J T^{n} x_{n}\right\|\right) \\
&= \alpha_{n} \phi\left(w, x_{n}\right)+\left(1-\alpha_{n}\right) \phi\left(w, T^{n} x_{n}\right)-\alpha_{n}\left(1-\alpha_{n}\right) g\left(\left\|J x_{n}-J T^{n} x_{n}\right\|\right) \\
& \leq \alpha_{n} \phi\left(w, x_{n}\right)+\left(1-\alpha_{n}\right)\left(1+\mu_{n}\right) \phi\left(w, x_{n}\right)+\xi_{n}\left(1-\alpha_{n}\right) \\
&-\alpha_{n}\left(1-\alpha_{n}\right) g\left(\left\|J x_{n}-J T^{n} x_{n}\right\|\right) \\
& \leq \phi\left(w, x_{n}\right)+\mu_{n} \phi\left(w, x_{n}\right)+\xi_{n}-\alpha_{n}\left(1-\alpha_{n}\right) g\left(\left\|J x_{n}-J T^{n} x_{n}\right\|\right) \\
& \leq \phi\left(w, x_{n}\right)+\mu_{n} M_{n}+\xi_{n}-\alpha_{n}\left(1-\alpha_{n}\right) g\left(\left\|J x_{n}-J T^{n} x_{n}\right\|\right) .
\end{aligned}
$$

It follows that

$$
\alpha_{n}\left(1-\alpha_{n}\right) g\left(\left\|J x_{n}-J T^{n} x_{n}\right\|\right) \leq \phi\left(w, x_{n}\right)-\phi\left(w, u_{n, i}\right)+\mu_{n} M_{n}+\xi_{n}
$$

Notice that

$$
\begin{aligned}
\phi\left(w, x_{n}\right)-\phi\left(w, u_{n, i}\right) & =\left\|x_{n}\right\|^{2}-\left\|u_{n, i}\right\|^{2}-2\left\langle w, J x_{n}-J u_{n, i}\right\rangle \\
& \leq\left\|x_{n}-u_{n, i}\right\|\left(\left\|x_{n}\right\|+\left\|u_{n, i}\right\|\right)+2\|w\|\left\|J x_{n}-J u_{n, i}\right\| .
\end{aligned}
$$

It follows from (2.1) and (2.2) that $\phi\left(w, x_{n}\right)-\phi\left(w, u_{n, i}\right) \rightarrow 0$ as $n \rightarrow \infty$. In view of $\liminf _{n \rightarrow \infty} \alpha_{n}\left(1-\alpha_{n}\right)>0$, we see that $\lim _{n \rightarrow \infty} g\left(\left\|J x_{n}-J T^{n} x_{n}\right\|\right)=0$. It follows from the property of $g$ that

$$
\lim _{n \rightarrow \infty}\left\|J x_{n}-J T^{n} x_{n}\right\|=0
$$

Since $x_{n} \rightarrow p$ as $n \rightarrow \infty$ and $J: E \rightarrow E^{*}$ is demi-continuous, we obtain that $J x_{n} \rightarrow J p \in E^{*}$. Note that

$$
\left|\left\|J x_{n}\right\|-\|J p\|\right|=\left|\left\|x_{n}\right\|-\|p\|\right| \leq\left\|x_{n}-p\right\| .
$$


This implies that $\left\|x_{n}\right\| \rightarrow\|J p\|$ as $n \rightarrow \infty$. Since $E^{*}$ enjoys the Kadec-Klee property, we see that

$$
\lim _{n \rightarrow \infty}\left\|J x_{n}-J p\right\|=0 .
$$

Notice that

$$
\left\|J T^{n} x_{n}-J p\right\| \leq\left\|J T^{n} x_{n}-J x_{n}\right\|+\left\|J x_{n}-J p\right\| .
$$

It follows from (2.3) and (2.4) that

$$
\lim _{n \rightarrow \infty}\left\|J T^{n} x_{n}-J p\right\|=0
$$

Note that $J^{-1}: E^{*} \rightarrow E$ is demi-continuous. It follows that $T^{n} x_{n} \rightarrow p$. On the other hand, we have

$$
\left|\left\|T^{n} x_{n}\right\|-\|p\|\right|=\left|\left\|J T^{n} x_{n}\right\|-\|J p\|\right| \leq\left\|J T^{n} x_{n}-J p\right\| .
$$

In view of (2.5), we obtain that $\left\|T^{n} x_{n}\right\| \rightarrow\|p\|$ as $n \rightarrow \infty$. Since $E$ enjoys the Kadec-Klee property, we obtain that

$$
\lim _{n \rightarrow \infty}\left\|T^{n} x_{n}-p\right\|=0 .
$$

Note that

$$
\left\|T^{n+1} x_{n}-p\right\| \leq\left\|T^{n+1} x_{n}-T^{n} x_{n}\right\|+\left\|T^{n} x_{n}-p\right\| .
$$

It follows from the asymptotic regularity of $T$ and (2.6) that

$$
\lim _{n \rightarrow \infty}\left\|T^{n+1} x_{n}-p\right\|=0
$$

That is, $T T^{n} x_{n}-p \rightarrow 0$ as $n \rightarrow \infty$. It follows from the closedness of $T$ that $T p=p$.

Next, we show that $p \in \bigcap_{i \in \Delta} E F\left(F_{i}\right)$. Notice that $\phi\left(w, y_{n}\right) \leq \phi\left(w, x_{n}\right)+\mu_{n} M_{n}+\xi_{n}$. In view of $u_{n, i}=S_{r_{n, i}} y_{n}$, we find from Lemma 1.8 that

$$
\begin{aligned}
\phi\left(u_{n, i}, y_{n}\right) & =\phi\left(S_{r_{n, i}} y_{n}, y_{n}\right) \\
& \leq \phi\left(w, y_{n}\right)-\phi\left(w, S_{r_{n, i}} y_{n}\right) \\
& \leq \phi\left(w, x_{n}\right)-\phi\left(w, S_{r_{n, i}} y_{n}\right)+\mu_{n} M_{n}+\xi_{n} \\
& =\phi\left(w, x_{n}\right)-\phi\left(w, u_{n, i}\right)+\mu_{n} M_{n}+\xi_{n} .
\end{aligned}
$$

This in turn implies that

$$
\lim _{n \rightarrow \infty} \phi\left(u_{n, i}, y_{n}\right)=0 .
$$

It follows from (1.2) that $\left\|u_{n, i}\right\|-\left\|y_{n}\right\| \rightarrow 0$ as $n \rightarrow \infty$. In view of $u_{n, i} \rightarrow p$ as $n \rightarrow \infty$, we arrive at $\lim _{n \rightarrow \infty}\left\|y_{n}\right\|=\|p\|$. It follows that $\lim _{n \rightarrow \infty}\left\|J y_{n}\right\|=\|J p\|$. Since $E^{*}$ is reflexive, we 
may assume that $J y_{n} \rightarrow f^{*} \in E^{*}$. In view of $J(E)=E^{*}$, we see that there exists $f \in E$ such that $J f=f^{*}$. It follows that

$$
\phi\left(u_{n, i}, y_{n}\right)=\left\|u_{n, i}\right\|^{2}-2\left\langle u_{n, i}, J y_{n}\right\rangle+\left\|J y_{n}\right\|^{2} .
$$

Taking $\liminf n_{n \rightarrow \infty}$ on the both sides of the equality above yields that

$$
\begin{aligned}
0 & \geq\|p\|^{2}-2\left\langle p, f^{*}\right\rangle+\left\|f^{*}\right\|^{2} \\
& =\|p\|^{2}-2\langle p, J f\rangle+\|J f\|^{2} \\
& =\|p\|^{2}-2\langle p, J f\rangle+\|f\|^{2} \\
& =\phi(p, f) .
\end{aligned}
$$

That is, $p=f$, which in turn implies that $f^{*}=J p$. It follows that $J y_{n} \rightarrow J p \in E^{*}$. Since $E^{*}$ enjoys the Kadec-Klee property, we obtain that $J y_{n}-J p \rightarrow 0$ as $n \rightarrow \infty$. Note that $J^{-1}: E^{*} \rightarrow E$ is demi-continuous. It follows that $y_{n} \rightarrow p$. Since $E$ enjoys the Kadec-Klee property, we obtain that $y_{n} \rightarrow p$ as $n \rightarrow \infty$. Notice that $\left\|u_{n, i}-y_{n}\right\| \leq\left\|u_{n, i}-p\right\|+\left\|p-y_{n}\right\|$. It follows that

$$
\lim _{n \rightarrow \infty}\left\|u_{n, i}-y_{n}\right\|=0
$$

Since $J$ is uniformly norm-to-norm continuous on any bounded sets, we have

$$
\lim _{n \rightarrow \infty}\left\|J u_{n, i}-J y_{n}\right\|=0
$$

From the assumption $r_{n, i} \geq a_{i}$, we see that

$$
\lim _{n \rightarrow \infty} \frac{\left\|J u_{n, i}-J y_{n}\right\|}{r_{n, i}}=0 \text {. }
$$

Notice that

$$
F_{i}\left(u_{n, i}, y\right)+\frac{1}{r_{n, i}}\left\langle y-u_{n, i}, J u_{n, i}-J y_{n}\right\rangle \geq 0, \quad \forall y \in C .
$$

It follows from condition (A2) that

$$
\left\|y-u_{n, i}\right\| \frac{\left\|J u_{n, i}-J y_{n}\right\|}{r_{n, i}} \geq \frac{1}{r_{n, i}}\left\langle y-u_{n, i}, J u_{n, i}-J y_{n}\right\rangle \geq F_{i}\left(y, u_{n, i}\right), \quad \forall y \in C .
$$

By taking the limit as $n \rightarrow \infty$ in the above inequality, from condition (A4) we obtain that

$$
F_{i}(y, p) \leq 0, \quad \forall y \in C
$$

For $0<t_{i}<1$ and $y \in C$, define $y_{t_{i}}=t_{i} y+\left(1-t_{i}\right) p$. It follows that $y_{t, i} \in C$, which yields that $F_{i}\left(y_{t, i}, p\right) \leq 0$. It follows from conditions (A1) and (A4) that

$$
0=F_{i}\left(y_{t, i}, y_{t, i}\right) \leq t_{i} F_{i}\left(y_{t, i}, y\right)+\left(1-t_{i}\right) F_{i}\left(y_{t, i}, p\right) \leq t_{i} F_{i}\left(y_{t, i}, y\right) .
$$


That is,

$$
F_{i}\left(y_{t, i}, y\right) \geq 0
$$

Letting $t_{i} \downarrow 0$, we find from condition (A3) that $F_{i}(p, y) \geq 0, \forall y \in C$. This implies that $p \in E P\left(F_{i}\right)$. This completes the proof that $p \in \Omega$.

Finally, we prove that $p=\Pi_{\Omega} x_{0}$. From $x_{n}=\Pi_{C_{n}} x_{0}$, we see that

$$
\left\langle x_{n}-z, J x_{0}-J x_{n}\right\rangle \geq 0, \quad \forall z \in C_{n} .
$$

In view of $\Omega \subset C_{n}$, we find that

$$
\left\langle x_{n}-w, J x_{0}-J x_{n}\right\rangle \geq 0, \quad \forall w \in \Omega
$$

Letting $n \rightarrow \infty$ in the above inequality, we see that

$$
\left\langle p-w, J x_{0}-J p\right\rangle \geq 0, \quad \forall w \in \Omega
$$

In view of Lemma 1.7, we can obtain that $p=\Pi_{\Omega} x_{0}$. This completes the proof.

If $T$ is asymptotically quasi- $\phi$-nonexpansive, then we find from Theorem 2.1 the following result.

Corollary 2.2 Let E be a uniformly smooth and strictly convex Banach space which also enjoys the Kadec-Klee property, and let $C$ be a nonempty closed and convex subset of E. Let $\Delta$ be an index set. Let $F_{i}$ be a bifunction from $C \times C$ to $\mathbb{R}$ satisfying (A1)-(A4) for every $i \in \Delta$. Let $T: C \rightarrow C$ be an asymptotically quasi- $\phi$-nonexpansive mapping. Assume that $T$ is closed asymptotically regular on $C$ and $\Omega:=F(T) \cap \bigcap_{i \in \Delta} E F\left(F_{i}\right)$ is nonempty and bounded. Let $\left\{x_{n}\right\}$ be a sequence generated in the following manner:

$$
\left\{\begin{array}{l}
x_{0} \in E, \quad \text { chosen arbitrarily, } \\
C_{1, i}=C, \\
C_{1}=\bigcap_{i \in \Delta} C_{1, i}, \\
x_{1}=\prod_{C_{1}} x_{0}, \\
y_{n}=J^{-1}\left(\alpha_{n} J x_{n}+\left(1-\alpha_{n}\right) J T^{n} x_{n}\right), \\
u_{n, i} \in C \text { such that } F_{i}\left(u_{n, i}, y\right)+\frac{1}{r_{n, i}}\left\langle y-u_{n, i} J u_{n, i}-J y_{n}\right\rangle \geq 0, \quad \forall y \in C, \\
C_{n+1, i}=\left\{z \in C_{n}: \phi\left(z, u_{n, i}\right) \leq \phi\left(z, x_{n}\right)+\mu_{n} M_{n}\right\}, \\
C_{n+1}=\bigcap_{i \in \Delta} C_{n+1, i}, \\
x_{n+1}=\Pi_{C_{n+1}} x_{0},
\end{array}\right.
$$

where $M_{n}=\sup \left\{\phi\left(z, x_{n}\right): z \in \Omega\right\},\left\{\alpha_{n}\right\}$ is a real number sequence in $(0,1)$ such that $\liminf _{n \rightarrow \infty} \alpha_{n}\left(1-\alpha_{n}\right)>0,\left\{r_{n, i}\right\}$ is a real number sequence in $\left[a_{i}, \infty\right)$, where $\left\{a_{i}\right\}$ is a positive real number sequence. Then the sequence $\left\{x_{n}\right\}$ converges strongly to $\Pi_{\Omega} x_{0}$, where $\Pi_{\Omega}$ is the generalized projection from $E$ onto $\Omega$. 
Remark 2.3 Since the index set $\Delta$ is arbitrary, Corollary 2.2 is an improvement of the corresponding results in Kim [25].

Remark 2.4 Corollary 2.2 also improves the corresponding results in Qin et al. [5] in the following aspects:

(a) from a uniformly smooth and uniformly convex space to a uniformly smooth and strictly convex Banach space which also enjoys the Kadec-Klee property;

(b) from a single bifunction to a family of bifunctions;

(c) from a quasi- $\phi$-nonexpansive mapping to an asymptotically quasi- $\phi$-nonexpansive mapping.

In the framework of Hilbert spaces, the theorem is reduced to the following.

Corollary 2.5 Let E be a Hilbert space, and let $C$ be a nonempty closed and convex subset of $E$. Let $\Delta$ be an index set. Let $F_{i}$ be a bifunction from $C \times C$ to $\mathbb{R}$ satisfying (A1)-(A4) for every $i \in \Delta$. Let $T: C \rightarrow C$ be a generalized asymptotically quasi-nonexpansive mapping. Assume that $T$ is closed asymptotically regular on $C$ and $\Omega:=F(T) \cap \bigcap_{i \in \Delta} E F\left(F_{i}\right)$ is nonempty and bounded. Let $\left\{x_{n}\right\}$ be a sequence generated in the following manner:

$$
\left\{\begin{array}{l}
x_{0} \in E, \quad \text { chosen arbitrarily, } \\
C_{1, i}=C, \\
C_{1}=\bigcap_{i \in \Delta} C_{1, i}, \\
x_{1}=\prod_{C_{1}} x_{0}, \\
y_{n}=\alpha_{n} x_{n}+\left(1-\alpha_{n}\right) T^{n} x_{n}, \\
u_{n, i} \in C \text { such that } F_{i}\left(u_{n, i}, y\right)+\frac{1}{r_{n, i}}\left\langle y-u_{n, i}, u_{n, i}-y_{n}\right\rangle \geq 0, \quad \forall y \in C, \\
C_{n+1, i}=\left\{z \in C_{n}:\left\|z-u_{n, i}\right\|^{2} \leq\left\|z-x_{n}\right\|^{2}+\mu_{n} M_{n}+\xi_{n}\right\}, \\
C_{n+1}=\bigcap_{i \in \Delta} C_{n+1, i}, \\
x_{n+1}=\operatorname{Proj}_{C_{n+1}} x_{0},
\end{array}\right.
$$

where $M_{n}=\sup \left\{\left\|z-x_{n}\right\|^{2}: z \in \Omega\right\},\left\{\alpha_{n}\right\}$ is a real number sequence in $(0,1)$ such that $\liminf _{n \rightarrow \infty} \alpha_{n}\left(1-\alpha_{n}\right)>0,\left\{r_{n, i}\right\}$ is a real number sequence in $\left[a_{i}, \infty\right)$, where $\left\{a_{i}\right\}$ is a positive real number sequence. Then the sequence $\left\{x_{n}\right\}$ converges strongly to $\operatorname{Proj}_{\Omega} x_{0}$, where $\operatorname{Proj}_{\Omega}$ is the metric projection from $E$ onto $\Omega$.

Proof In the framework of Hilbert spaces, we find that $\phi(x, y)=\|x-y\|^{2}, J$ is reduced to the identity mapping and the generalized projection $\Pi_{C}$ is reduced to the metric projection $\operatorname{Proj}_{C}$. This completes the proof.

For a single bifunction, we also have the following.

Corollary 2.6 Let E be a Hilbert space, and let $C$ be a nonempty closed and convex subset of E. Let $F$ be a bifunction from $C \times C$ to $\mathbb{R}$ satisfying (A1)-(A4). Let $T: C \rightarrow C$ be a generalized asymptotically quasi-nonexpansive mapping. Assume that $T$ is closed asymptotically regular on $C$ and $\Omega:=F(T) \cap E F(F)$ is nonempty and bounded. Let $\left\{x_{n}\right\}$ be a sequence 
generated in the following manner:

$$
\left\{\begin{array}{l}
x_{0} \in E, \quad \text { chosen arbitrarily, } \\
C_{1}=C, \\
x_{1}=\Pi_{C_{1}} x_{0}, \\
y_{n}=\alpha_{n} x_{n}+\left(1-\alpha_{n}\right) T^{n} x_{n}, \\
u_{n} \in C \text { such that } F\left(u_{n}, y\right)+\frac{1}{r_{n}}\left\langle y-u_{n}, u_{n}-y_{n}\right\rangle \geq 0, \quad \forall y \in C, \\
C_{n+1}=\left\{z \in C_{n}:\left\|z-u_{n}\right\|^{2} \leq\left\|z-x_{n}\right\|^{2}+\mu_{n} M_{n}+\xi_{n}\right\}, \\
x_{n+1}=\operatorname{Proj}_{C_{n+1}} x_{0},
\end{array}\right.
$$

where $M_{n}=\sup \left\{\left\|z-x_{n}\right\|^{2}: z \in \Omega\right\},\left\{\alpha_{n}\right\}$ is a real number sequence in $(0,1)$ such that $\liminf _{n \rightarrow \infty} \alpha_{n}\left(1-\alpha_{n}\right)>0,\left\{r_{n, i}\right\}$ is a real number sequence in $[a, \infty)$, where a is a positive real number. Then the sequence $\left\{x_{n}\right\}$ converges strongly to $\operatorname{Proj}_{\Omega} x_{0}$, where $\operatorname{Proj}_{\Omega}$ is the metric projection from $E$ onto $\Omega$.

Proof In the framework of Hilbert spaces, we find that $\phi(x, y)=\|x-y\|^{2}, J$ is reduced to the identity mapping, and the generalized projection $\Pi_{C}$ is reduced to the metric projection $\operatorname{Proj}_{C}$. In view of Corollary 2.5, we may immediately conclude the desired results.

\section{Competing interests}

The author declares that he has no competing interests.

\section{Acknowledgements}

The author is grateful to the editor and the anonymous reviewers for suggestions which improved the contents of the article.

Received: 22 July 2013 Accepted: 22 August 2013 Published: 8 September 2013

\section{References}

1. Alber, Yl: Metric and generalized projection operators in Banach spaces: properties and applications. In: Kartsatos, AG (ed.) Theory and Applications of Nonlinear Operators of Accretive and Monotone Type. Dekker, New York (1996)

2. Agarwal, RP, Cho, YJ, Qin, X: Generalized projection algorithms for nonlinear operators. Numer. Funct. Anal. Optim. 28, 1197-1215 (2007)

3. Qin, X, Su, Y, Wu, C, Liu, K: Strong convergence theorems for nonlinear operators in Banach spaces. Commun. Appl. Nonlinear Anal. 14, 35-50 (2007)

4. Zhou, H, Gao, G, Tan, B: Convergence theorems of a modified hybrid algorithm for a family of quasi- $\boldsymbol{\phi}$-asymptotically nonexpansive mappings. J. Appl. Math. Comput. 32, 453-464 (2010)

5. Qin, X, Cho, YJ, Kang, SM: Convergence theorems of common elements for equilibrium problems and fixed point problems in Banach spaces. J. Comput. Appl. Math. 225, 20-30 (2009)

6. Qin, X, Cho, SY, Kang, SM: On hybrid projection methods for asymptotically quasi- $\phi$-nonexpansive mappings. Appl. Math. Comput. 215, 3874-3883 (2010)

7. Qin, X, Agarwal, RP, Cho, SY, Kang, SM: Convergence of algorithms for fixed points of generalized asymptotically quasi- $\phi$-nonexpansive mappings with applications. Fixed Point Theory Appl. 2012, Article ID 58 (2012)

8. Agarwal, RP, Qin, X, Kang, SM: An implicit iterative algorithm with errors for two families of generalized asymptotically nonexpansive mappings. Fixed Point Theory Appl. 2011, Article ID 58 (2011)

9. Blum, E, Oettli, W: From optimization and variational inequalities to equilibrium problems. Math. Stud. 63, 123-145 (1994)

10. Kang, SM, Cho, SY, Liu, Z: Convergence of iterative sequences for generalized equilibrium problems involving inverse-strongly monotone mappings. J. Inequal. Appl. 2010, Article ID 827082 (2010)

11. Yang, S, Li, W: Iterative solutions of a system of equilibrium problems in Hilbert spaces. Adv. Fixed Point Theory 1 , 15-26 (2011)

12. Qin, $X$, Cho, SY, Kang, SM: Iterative algorithms for variational inequality and equilibrium problems with applications. J. Glob. Optim. 48, 423-445 (2010)

13. Ye, J, Huang, J: Strong convergence theorems for fixed point problems and generalized equilibrium problems of three relatively quasi-nonexpansive mappings in Banach spaces. J. Math. Comput. Sci. 1, 1-18 (2011)

14. Cho, SY, Kang, SM: Approximation of fixed points of pseudocontraction semigroups based on a viscosity iterative process. Appl. Math. Lett. 24, 224-228 (2011) 
15. Zegeye, $\mathrm{H}$, Shahzad, N: Strong convergence theorem for a common point of solution of variational inequality and fixed point problem. Adv. Fixed Point Theory 2, 374-397 (2012)

16. Cho, SY, Li, W, Kang, SM: Convergence analysis of an iterative algorithm for monotone operators. J. Inequal. Appl. 2013, Article ID 199 (2013)

17. Kim, JK: Hybrid projection algorithms for generalized equilibrium problems and strictly pseudocontractive mappings. J. Inequal. Appl. 2010, Article ID 312602 (2010)

18. Abdel-Salam, HS, Al-Khaled, K: Variational iteration method for solving optimization problems. J. Math. Comput. Sci. 2, 1475-1497 (2012)

19. Qin, X, Cho, SY, Kang, SM: Strong convergence of shrinking projection methods for quasi- $\boldsymbol{\phi}$-nonexpansive mappings and equilibrium problems. J. Comput. Appl. Math. 234, 750-760 (2010)

20. Yuan, Q, Kim, JK: Weak convergence of algorithms for asymptotically strict pseudocontractions in the intermediate sense and equilibrium problems. Fixed Point Theory Appl. 2012, Article ID 132 (2012)

21. Cho, SY, Kang, SM: Zero point theorems for $m$-accretive operators in a Banach space. Fixed Point Theory 13, 49-58 (2012)

22. Takahashi, W, Zembayashi, K: Strong and weak convergence theorems for equilibrium problems and relatively nonexpansive mappings in Banach spaces. Nonlinear Anal. 70, 45-57 (2009)

23. Cho, SY, Kang, SM: Approximation of common solutions of variational inequalities via strict pseudocontractions. Acta Math. Sci. 32, 1607-1618 (2012)

24. Kim, JK: Some results on generalized equilibrium problems involving strictly pseudocontractive mappings. Acta Math. Sci. 31, 2041-2057 (2011)

25. Kim, JK: Strong convergence theorems by hybrid projection methods for equilibrium problems and fixed point problems of the asymptotically quasi- $\boldsymbol{\phi}$-nonexpansive mappings. Fixed Point Theory Appl. 2011, Article ID 10 (2011)

26. Qin, X, Cho, SY, Kang, SM: An extragradient-type method for generalized equilibrium problems involving strictly pseudocontractive mappings. J. Glob. Optim. 49, 679-693 (2011)

27. Agarwal, RP, Verma, RU: General implicit variational inclusion problems based on A-maximal (m)-relaxed monotonicity (AMRM) frameworks. Appl. Math. Comput. 215, 367-379 (2009)

28. Wang, Z, Lou, W: A new iterative algorithm of common solutions to quasi-variational inclusion and fixed point problems. J. Math. Comput. Sci. 3, 57-72 (2013)

29. Wu, C, Liu, A: Strong convergence of a hybrid projection iterative algorithm for common solutions of operator equations and of inclusion problems. Fixed Point Theory Appl. 2012, Article ID 90 (2012)

30. Cho, SY: Hybrid projection algorithms for treating common fixed points of a family of demicontinuous pseudocontractions. Appl. Math. Lett. 25, 854-857 (2012)

31. Lu, J, Gu, F: Projection methods of iterative solutions in Hilbert spaces. Fixed Point Theory Appl. 2012, Article ID 162 (2012)

32. Qin, X, Chang, SS, Cho, YJ: Iterative methods for generalized equilibrium problems and fixed point problems with applications. Nonlinear Anal. 11, 2963-2972 (2010)

33. Chang, SS, Lee, HWJ, Chan, CK: A new hybrid method for solving a generalized equilibrium problem, solving a variational inequality problem and obtaining common fixed points in Banach spaces. Nonlinear Anal. 73, 2260-2270 (2010)

34. Li, HY, Su, Y: Strong convergence theorem by a new hybrid method for equilibrium problems and variational inequality problems. Nonlinear Anal. 72, 847-855 (2010)

35. Chang, SS, Kim, JK, Wang, L: Total quasi- $\phi$-asymptotically nonexpansive semigroups and strong convergence theorems in Banach spaces. Fixed Point Theory Appl. 2012, Article ID 153 (2012)

36. Zǎlinescu, C: On uniformly convex functions. J. Math. Anal. Appl. 95, 344-374 (1983)

doi:10.1186/1029-242X-2013-425

Cite this article as: Zhang: Common solutions of equilibrium and fixed point problems. Journal of Inequalities and Applications 2013 2013:425.

\section{Submit your manuscript to a SpringerOpen ${ }^{\circ}$ journal and benefit from:}

- Convenient online submission

- Rigorous peer review

- Immediate publication on acceptance

Open access: articles freely available online

- High visibility within the field

- Retaining the copyright to your article 